\title{
Wir arbeiten konsequent weiter!
}

Mittlerweile halten Sie die zweite Ausgabe der Zeitschrift Sport- und Präventivmedizin in Ihren Händen. Die vielen uns entgegengebrachten positiven Reaktionen bestärken uns, diesen Weg weiterzugehen.

Eine Zeitschrift lebt von den Inhalten und der interaktiven Kommunikation zu den Lesern und Leserinnen, weshalb wir Sie herzlichst dazu einladen, uns interessante Beiträge oder Leserbriefe zu übermitteln (Lesen Sie dazu bitte die Autorenrichtlinien und benutzen Sie bitte die diesbezüglichen Formatvorlagen: Heft 1-2009, Seite 42 oder online unter http://www.springer.com/springerwiennewyork/medicine/journal/12534.

Ein starkes, vielseitiges und vor allem gern gelesenes Medium trägt wesentlich dazu bei, die Bedeutung der interdisziplinären Sport- und Präventivmedizin für die Gegenwart und Zukunft unseres Gesundheitssystems zu untermauern.

Die aktuelle Ausgabe der Zeitschrift, die sich mit dem Schwerpunktthema „Herzkreislauf und Sport" beschäftigt, ist von allen Autoren Herrn Prim. Univ.-Prof. Dr. Peter Schmid, einem der renommiertesten Sportkardiologen Österreichs, zum 60. Geburtstag gewidmet. Lesen Sie dazu eine sehr persönliche Laudatio, die nicht nur die fachlichen, sondern auch menschlichen Qualitäten dieser Persönlichkeit unterstreicht.

Univ.-Prof. Dr. Norbert Bachl Herausgeber

\section{Dr. Piero Lercher}

Editor in chief

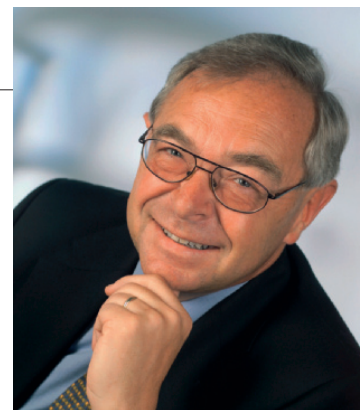

HERAUSGEBER

Univ.-Prof.

Dr. Norbert Bachl

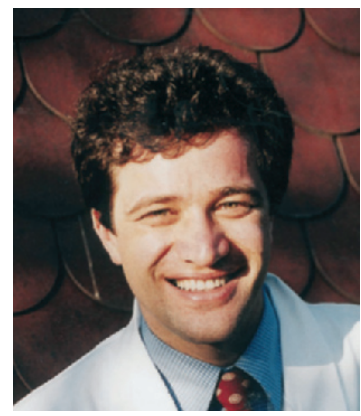

EDITOR IN CHIEF

Dr. Piero Lercher 